\title{
A Fuzzy Approach to Assess the Perception of a Rural Community Concerning the Impact of Distributed Power Generation on Local Sustainability
}

\author{
Eduardo Teixeira da Silva ${ }^{\text {* }}$ \\ https://orcid.org/0000-0001-5424-4455
}

\section{Márcio André Fernandes Martins'}

https://orcid.org/0000-0003-2390-1525

\section{Adonias Magdiel Silva Ferreira ${ }^{1}$}

https://orcid.org/0000-0003-3685-3809

\section{Jorge Laureano Moya Rodriguez ${ }^{1}$}

https://orcid.org/0000-0003-0541-0191

${ }^{1}$ Federal University of Bahia, Industrial Engineering Program, Polytechnic School, Brazil.

Editor-in-Chief: Alexandre Rasi Aoki

Associate Editor: Alexandre Rasi Aoki

Received: 2020.07.28; Accepted: 2021.03.04.

*Correspondence: edudjey@gmail.com; Tel. +55-71-985424300 (E.T.S.).

\section{HIGHLIGHTS}

- A Fuzzy logic was applied to assess the sustainability impact of distributed electricity generation.

- According to the defined sustainability scale, the perception of the rural community presented an parcially sustainable score of the index.

- $\quad$ The results of the applied model were consistent with the research object in rural communities and can be replicated in similar studies.

Abstract: This paper aims to evaluate the perception of residents of a rural quilombola community, about the impacts of distributed energy generation (DG) on the social, economic and environmental dimensions. The main challenge of the proposed model was to quantify the main perceptions of the target population of the research, as well as maintain the coherence of the specifications of the sustainability parameters. Diffuse modeling allows the transformation of linguistic variables into numerical values, the disadvantage is the dependence of the specialist to construct the rules. The methodology used was the application of a semistructured questionnaire, and the results were used as a reference to build the discourse domain of the input variables of the Fuzzy inference system, which generated an index of $54.1 \%$ classified in the category partially sustainable. Specifically, the economic and social dimensions obtained an index of $46.7 \%$ and the environmental dimension of $69 \%$. From the perspective of the perception of the respondents, the variables with the greatest impact were: landscape change $(\mathrm{LCH}) 92 \%$, environmental awareness (EA) and reduction of global warming (GW) with values of both $69 \%$. The variable of the most prominent economic dimension was: cost of the system with a value of $69 \%$. In the social dimension, the variables with the greatest impact were: Community Acceptability (AC), Expansion of the support network (ESN) with values of $69 \%$. The 
proposed model allowed us to interpret the respondents' perception, and can be used to generate effective actions that solve the identified demands.

Keywords: Distributed Generation; sustainability; Fuzzy logic; rural communities.

\section{INTRODUCTION}

The power generation in a distributed way has increased over the past decades. Academics, citizens and policymakers advocate the transition from the predominant centralized power generation system to a more decentralized configuration [1]. The Distributed power Generation (DG) in Brazil started in 1994 with the States and Municipalities Energy Development Program (PRODEEM). The PRODEEM, in turn, was incorporated into the Luz Para Todos Program (LpT) (Energy for Everyone Program) in 2003. Years later, in 2012, the $\mathrm{N}^{\circ} 482$ Normative Resolution was launched, which has established the general conditions and rules for accessing distributed micro and mini generation systems, besides it has created the Electric Energy Compensation System (SCEE) [2].

DG conceptually refers to the power generation mechanisms that, located close to the load or to the consumer, can be connected to the power grid or can meet an isolated system [3],[4]. The use of DG systems connected to the Centralized Power Generation (CG) offers benefits such as reduction of energy losses, improvement of voltage levels and the increase of the transmission capacity of the system [5]. This complementarity from DG in the electrical network makes the electrical supply system more reliable, as well as contributes to the minimization of problems arising from climate change [6],[7].

In 2015 Normative Resolution $N^{\circ} 482$ was amended by $N^{\circ} 687$. This has enabled the significant increase in $\mathrm{dg}$ insertion potential in the energy matrix, especially with traditional consumers who are beginning to produce their electricity. Until 2020 november, 272.255 consumer units were connected to the electricity grid in urban areas, equivalent to $88 \%$ of DG facilities in Brazil, only $12 \%$ were installed in rural areas [8]. In addition to the low percentage of DG facilities in rural areas, it is important to highlight other drawbacks that concern the great challenges these communities face in order to access technology, such as low family per capita income, lack of public policies, poor access to information on GD, high cost of the system, etc. The low percentage mentioned above is also related to the incipience of this type of technology for energy production, the long distances of urban centers, as well as maintenance logistics due to the low supply of local skilled labor. The concentration of GD in urban areas demonstrates the need for efforts in relation to care in rural areas. In this sense, evaluating the social, environmental and economic benefits that GD can generate in rural communities, through a tool that translates a subjective language into a mathematical language can contribute to promote the expansion of GD.

The literature has claimed that the implementation of renewable energies in DG could not be encouraged only by considering the benefits related to economic nature issues, such as the increase in the job opportunities, but also by achieving the social, environmental and political benefits [9],[10],[11].

The studies identified in the literature on DG-linked renewable energy in rural areas are mostly associated with isolated systems [12], besides the analysis of environmental, economic and social impacts is done in a segregated way. With regard to economic aspects, most of the available works addressed issues associated with the implementation and operation of DG such as electricity costs, network accessibility, maintenance and operation, whereas the works dealing with environmental aspects focused on pollutant emissions, noise, impact on the ecosystem, impact on wildlife and land use [13-15].

Regarding the research works that addressed social aspects, the focus is diversified and include topics such as work stations, governance and quality of life [15]; domestic benefits [16]; system acceptance and job opportunities [17]; social benefits [18]; improvements in access to the electricity [19]; technology acceptance [20]; equity, health and acceptance of the system [21]; society well-being, education and culture [22]; creation of jobs [23]. In this way, the systematic assessment in an integrated way of the social, economic and environmental impacts related to DG in rural communities is an open issue in the literature.

On the other hand, an experimental approach handling data in loco in rural communities, based on surveys applied to its members, is conducive to the influence of many sources of uncertainty. In this context, it is appropriate to use the evaluation model based on the fuzzy inference system. The literature indicates a wide use of fuzzy logic in different areas of knowledge; this illustrates its versatility, for example, in DG related systems. The fuzzy approach consists of working in scenarios with approximate and not precise reasoning [24]. Fuzzy inference systems allow us to handle inaccurate (subjective) information, described in natural language and transform it into a numerical format, as well as to solve problems in which its variables express 
inaccuracies, establishing a basis for modeling phenomena and processes in the accurate and social sciences [25-27]. Fuzzy logic has served as a basis for artificial intelligence and has been used by researchers to produce sustainability indicators in several areas such as industry [28]; energy management [29]; assessment of service quality [27]; urban areas [30]; selection of locations for installation of power plants [31]; power generation [32]; identification of sustainable territory [33]; university environments [34]; among others, this illustrates its versatility.

With regard to the research studies related to fuzzy inference system-based sustainability measures, one can highlight the works as follows. Rajak and Vinodh [28], fuzzy by measured social sustainability in an Indian organization for the manufacture of automotive components, alemded a diffuse index of social sustainability, and the importance of the performance of the index that social sustainability attributes. Another study developed by Haider in small urban neighborhoods presented a model that generates an output in the form of a thermometer and a sustainability diagram [30]. In another study, the authors Arcos et al, develop a diffuse logical control model of low complexity, adopted 25 rules, applied to an energy management system for a residential network connected to the electricity grid [29]. This same perspective, a fuzzy logic model is developed to select space locations for solar power plants in the province of Markazi, in Iran [31]. Likewise, the Fuzzy AHP (Analytic Hierarchy Process-FAHP) method is used to assess the quality of services in a large hotel, located in Santa Catarina-Brazil [27].

Another sustainability study is carried out in a university environment to evaluate the perception of the various actors who transit through it [34]. To this end, questionnaires are applied and a fuzzy model with an associated index is developed to present the level of sustainability of a Higher Education Institution (HEI). The author concludes that fuzzy inference systems are capable of assessing what can be realized by the university community about the sustainability of their institution. It is observed that, although there are studies that have addressed several applications of Fuzzy inference applied to sustainability, the literature has presented a research gap in the application of diffuse inference in the evaluation of the perception of the dimensions of sustainability on the demand side of DG systems connected to the electric network in rural communities.

It is worth noting that there has been a lot of progress in sustainability studies in isolated power generation systems in rural areas, however, we have not located in the literature studies that evaluate sustainability with the use of DG connected to the electricity grid in rural areas. Thus, to meet this gap, this work aims to develop a diffuse inference model to provide information that represents the systematic evaluation of associated impacts, the implementation of DG systems connected to the electricity grid in rural communities. In addition, contribute to the identification of the social, environmental and economic aspects most impacting of distributed generation, as well as can support the development of public policies for the target public, especially with regard to the acquisition and maintenance of systems.

\section{METHODS}

Seventy families participated in this study, one member of each family was invited to answer the questionnaire. Most of the participants in the research were service providers in the agricultural area, with incomplete elementary education and family income between 0.16 and 2 minimum wages.

\section{Instrument}

A questionnaire was used, produced by the researcher based on the literature of the area and consultation with specialists [35],[36]. The instrument was structured and parameterized by the Likert scale resource. In the first stage, questions are presented, the answers of which are between agreement (I agree/disagree) with a statement. And then, the intensity of agreement with the statement is measured. The Likert method is used as a standard psychometric escalation measurement to assess the responses of research participants. A Likert climbing measurement facilitates the construction and administration of research, as well as data encoding and analysis [25],[37]. From this, this instrument was structured in three blocks (social, environmental and economic). Each block was composed of 10 questions in Likert scale format, in which the participant presented some statements and needed to answer on a scale of 5 points, being 1-much and 5-totally satisfied [38]. Each question corresponds to weight according to the relevance of the question to the interviewees. Finally, questions related to sociodemographic data (age, gender, marital status, education, occupation and income range). The confidence level of the instrument was estimated and valid from the calculation performed on 17 observations in 30 items, generated an Alpha Coefficient of Cronbach $(\alpha=0.94)$, Equation (1) [39]. The confidence level of the instrument was estimated and valid from the calculation of Cronbach's Alpha Coefficient $(\alpha=0.94)$. The relevant literature considers satisfactory a 
research instrument that obtains $\alpha \geq 0.70$ [40],[41]. Furthermore, for the analyses, an electronic spreadsheet was used to insert the collected data and the Matlab software that assisted in the generation of the fuzzy inference model.

To calculate Cronbach alpha coefficient, the equation applies:

$$
\alpha=\frac{k}{k-1}\left(1-\frac{\sum_{i-1}^{k} s_{i}^{2}}{s_{\text {soma }}^{2}}\right)
$$

$k$ é o número de itens, $n$ é o número de respondentes.

$s_{i}^{2}$ é a variância dos $n$ escores das pessoas a $i$-ésimo item $(i=1, \ldots, k)$,

$s^{2}$ soma é a variância dos totais $\operatorname{Tj}(j=1,2, \ldots, n)$. de escores de cada respondente.

\section{Procedures}

For data collection, two visits were made to the Quilombola Monjolo community, located in the interior of the state of Rio Grande do Sul/Brazil, in the city of São Lourenço do Sul, located at an altitude of $220 \mathrm{~m}$, in the geographic coordinates of $31^{\circ} 11^{\prime} 35.5^{\prime \prime}$ in the South and $52^{\circ} 21^{\prime 2} 22^{\prime \prime}$ in the West. The quilombola communities are defined as places of large concentrations of blacks, whose ancestors rebelled against the colonial slave regime, founding the quilombos. The term "quilombo" had its concept expanded in the Brazilian Federal Constitution of 1988 to cover all areas occupied by communities remaining from the former quilombos [42]. Brazil has 5,972 quilombola locations, divided into 1,672 municipalities. Being the highest concentration of quilombos in the State of Bahia 1,046, followed by Minas Gerais with 1,021, Maranhão and Pará with 866 quilombos, the state of Rio Grande do Sul concentrates 193 quilombos [43].

Data collection Occurred in February 2019, when the questionnaire was applied to respondents in this community. Two meetings were held with the residents, through scheduled meetings, through the board of the Quilombo Community Association. In the first meeting, the objective of the research was presented and the participants signed the term of Free and Informed Consent. In the second meeting, the questionnaire was applied with the presence of the researcher, who also entered the community for another four days, to make observations in the field.

Collection procedures are finished. A database was made, then the respective treatment was performed. During this process, it was identified that some questions were left unanswered. These were disregarded at the time of the analysis, without compromising the final results, because they were not the focus of the respective analyses. The results were used as a reference for the construction of the discourse domain of the input variables of the Fuzzy inference system. Already in possession of the database, and with the help of an electronic spreadsheet, economic, social and environmental indexes were analyzed and generated, as well as a general index with all the answers and weights considered. The Fuzzy inference model was generated using the Matlab software. The Fuzzy logic expresses the concept of partial truth and determines the values between the "completely true" (1) and "completely false" (0). This means that a Fuzzy logic value is a value assigned in the range 0 to 1 . In which the elements can belong to two or more Fuzzy sets. The use of the triangular membership function was defined for this type of problem, detailing of all these steps can be found in [44]. In this type of function the points $a$ and $c$ at the base of the triangle determine the interval where the membership function assumes values different than zero, point $b$ is the one where the maximum membership is verified. The function values are found on the vertical axis and the values of the variable analyzed on the horizontal axis and the triangular membership function is described by Equation (2).

$$
\mu(x)=\left\{\begin{array}{ccc}
0 & \text { se } & x \leq a \\
\frac{x-a}{b-a} & \text { se } & a \leq x \leq b \\
\frac{c-x}{c-b} & \text { se } & b \leq x \leq c \\
0 & \text { se } & x \leq c
\end{array}\right.
$$

The stages of the model building to assess the sustainability of DG with Fuzzy logic are shown in Figure 1. 


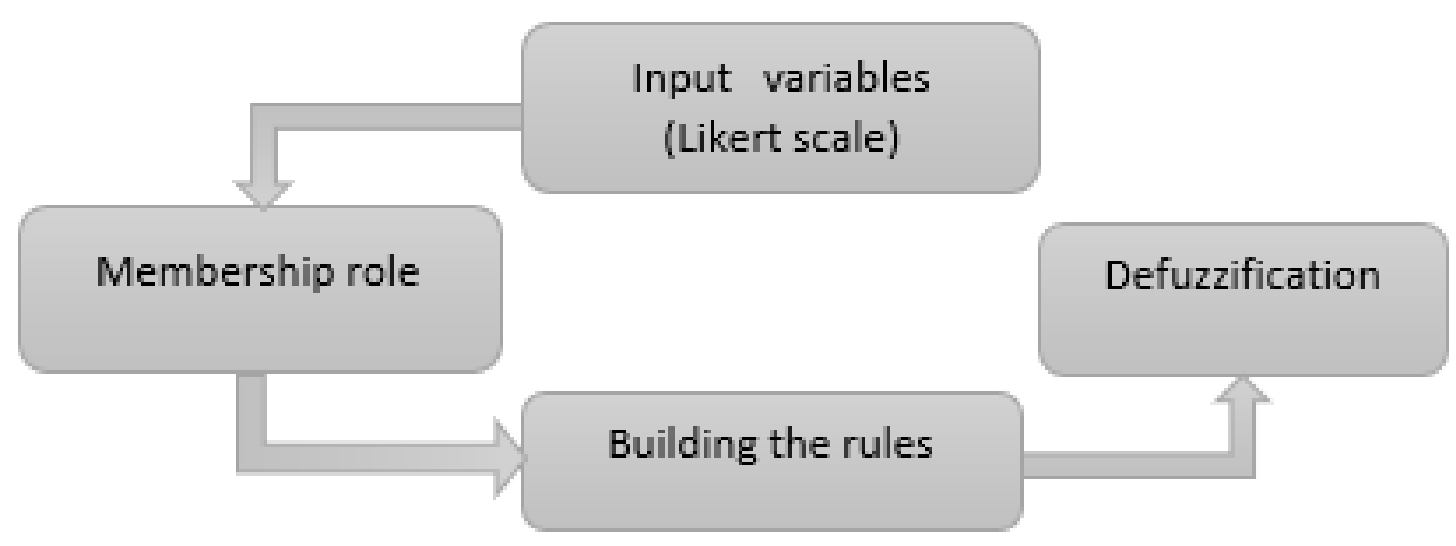

Figure 1. Stages of the DG sustainability assessment model with Fuzzy logic.

The general model was structured based on three dimensions, in which each one generates a specific index (economic, social and environmental). Therefore, a general index obtained represents the residents' perception of the DG related sustainability based on wind and solar photovoltaic energy sources from the combination of the indexes of each evaluated dimension.

The spreadsheet indexes were calculated from Equations (3), (4) and (5). The weighted value (VPi) resulting from the respondent's level of agreement and the assigned weight (degree of importance of the variable) was calculated by Equation (2).

$$
V P i=\left(\sum_{i=1}^{n} r i * i\right) *\left(\sum_{i=1}^{n} p i * i\right)
$$

Where: $V P i=$ Weighted sum; $n=$ number of variables; $r_{i}=$ Unit variable $i ; p_{i}=$ Weight of variable $i$.

Equation (4) was established to calculate the sustainability index for each dimension.

$$
S d i=\left(\frac{\sum_{i=1}^{n} V P i}{\operatorname{VPiMax} * N r}\right) * 100
$$

Where: Sdi = sustainability index i; n number of variables; VPiMax = Maximum weighted sum value; $\mathrm{Nr}$ amount of respondents.

Equation (5) was used to calculate the global sustainability of DG.

$$
S G=\left(\frac{\sum_{i=1}^{n} S d i}{\sum_{i=1}^{n} \operatorname{VPiMax*Nr}}\right) * 100
$$

Where: $S G=$ Overall sustainability of the impact on DG.; $n$ number of variables; $\mathrm{Nr}$ amount of respondents.

The data handling identified that some respondents did not answer all the questions because they did not have the knowledge or experience some subjects covered in the questionnaire, however, it was not representative to interfere in the analysis and compilation of the collected data.

\section{RESULTS AND DISCUSSION}

The sample analysis of the questionnaire uses the Likert scale to make it possible to evaluate the responses by contribution group according to the value assigned to each variable (Figure 2). 


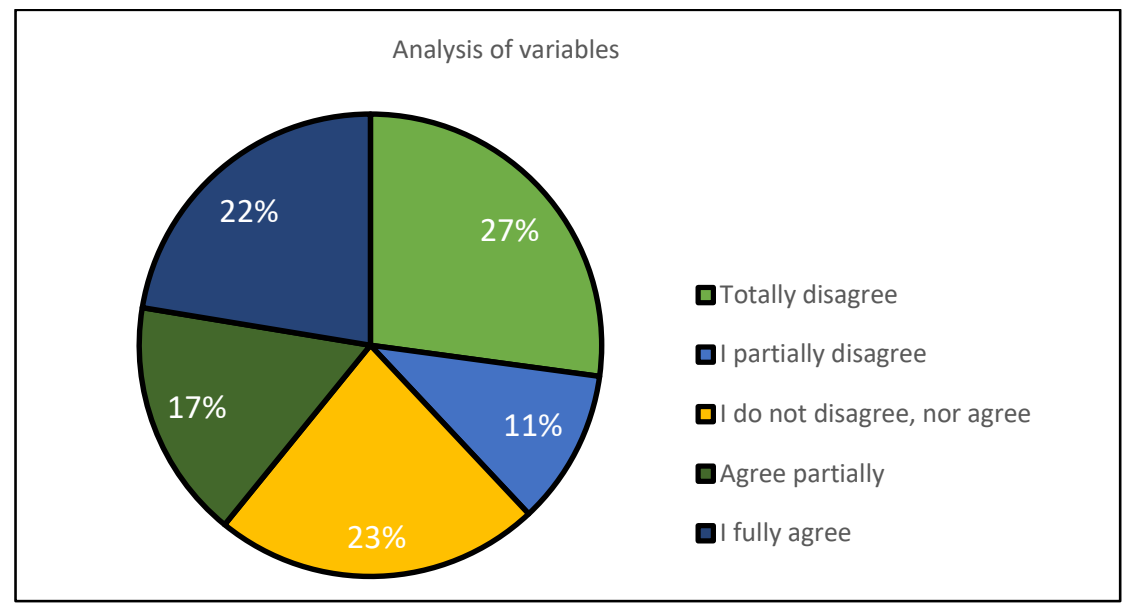

Figure 2. Percentage of questionnaire response variables.

Figure 3 shows the weight distribution of the questionnaire variables according to the degree of importance to the respondents.

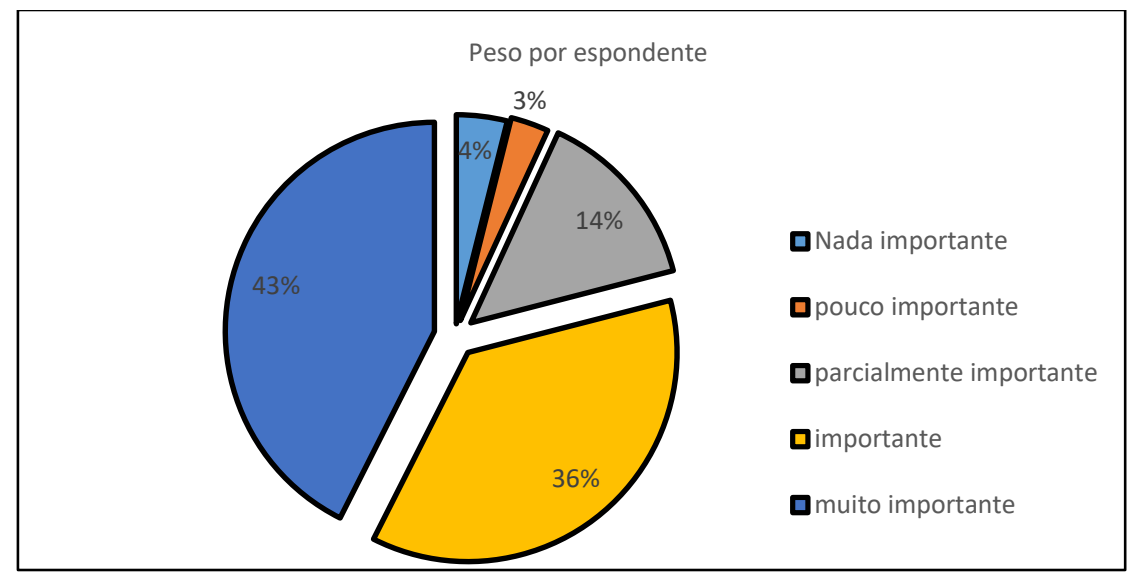

Figure 3. Weight of questions by the degree of importance.

The method used in this study provided a sustainability index for each of the evaluated variables and a general sustainability index with the implementation of DG (Table 1).

Table 1. Perception index of the DG related sustainability in the studied quilombola rural community

\begin{tabular}{lcc}
\hline Variables & Weighted Value & Index (\%) \\
\hline Environmental & 1811,76 & 45,27 \\
Economic & 2247,53 & 55,67 \\
Social & 1941,76 & 46,32 \\
\hline General index of sustainability & & $\mathbf{4 9 , 0 8}$ \\
\hline
\end{tabular}

Based on the results of the respondents' perception of DG related sustainability, the indices in Table 1 confirmed the community reality. As locally observed by the researcher, after the installation of the DG system, there was an increase in the three investigated sustainability dimensions, for example: with regard to the environmental aspect, separation of the residual material was generated, reduction of energy waste, discussion about the use of renewable energy sources, increased interest by the majority of the residents to generate their energy, to use solar water pumping and use of solar water heater for bathing water, use cisterns to collect rainwater, among others. Regarding the social dimension, the frequency of meetings increased, DG brought more visibility to the community, with visits from schools, universities, press 
publications, academic works, articles, visits from the surrounding community and the presence of government representatives. These actions have an impact on the economic aspect, with the increase in the sale of local products, the opening of new spaces for sale, as well as the reduction of the energy bill in the residence where the system was installed. Anyway, these results increased the community's autonomy, since quilombos in Brazil are among the most vulnerable communities in the country, it is one of the historically excluded groups, victims of structural racism, outside public policies and with a huge liability for land regularization, they suffer from a lack of citizenship and abandonment and the absence of affirmative public policies by the State[45],[46].

\section{Fuzzy model of sustainability perception from the DG}

To express the structure of the perception analysis of the actors that lead this study, a Fuzzy model based on the Mamdani inference systems was built, that is, the Max-Min type and the centroid method for the defuzzification at different levels, conceptual model in Figure 4.

\section{Impact of sustainability of distributed generation}

\section{Input linguistic variables}

\section{Output linguistic variables: Partial indexes}

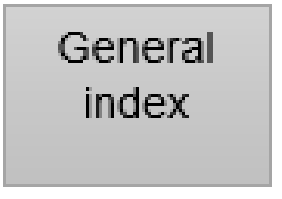

\section{Sustainability rating}

\section{Sustainabili ty index}

\section{Environmental awareness Reduces global warming Landscape changeLandscape change}

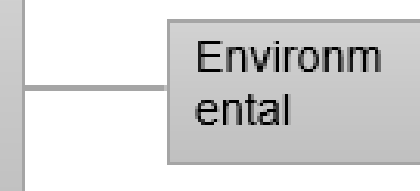

\section{System cost Incentive policies Electricity bill reduction}
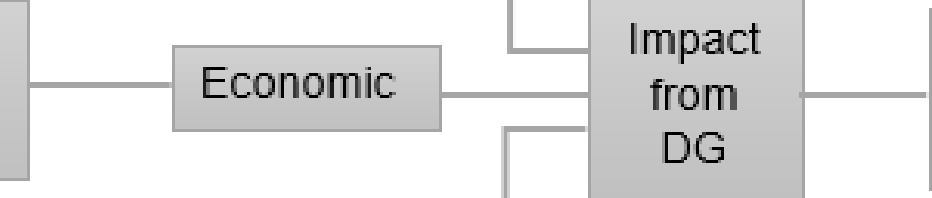

\section{Community acceptability} Expansion of the support network Job creation

Figure 4. Conceptual model of perception of the DG related sustainability.

Three models (social, environmental and economic) were built and nine input variables from the synthesis of the questions in the spreadsheet were used, as shown in Table 2. 
Table 2. Dimensions of impacts and indicators to characterize DG related sustainability in rural communities.

\begin{tabular}{|c|c|c|}
\hline Dimension & Indicators & Definition \\
\hline \multirow{3}{*}{ Environmental } & Environmental awareness (EA) & $\begin{array}{l}\text { It shows the attitude of perceiving the environment in } \\
\text { which it is inserted, learning to protect and take care of it. }\end{array}$ \\
\hline & Reduces global warming (GW) & $\begin{array}{l}\text { It considers the contribution of the DG system with } \\
\text { renewable sources in the reduction of greenhouse gas } \\
\text { emissions. }\end{array}$ \\
\hline & Landscape change (LCH) & $\begin{array}{l}\text { It evaluates if there has been any negative modification of } \\
\text { the landscape, generating an unpleasant sensation. }\end{array}$ \\
\hline \multirow{3}{*}{ Economic } & Cost System (CS) & $\begin{array}{l}\text { Evaluates equipment and installation costs. } \\
\text { Shows government actions to facilitate the acquisition and } \\
\text { installation of the system. }\end{array}$ \\
\hline & Incentive policies (IP) & $\begin{array}{l}\text { It evaluates how much the residence served by DG saves } \\
\text { with the energy of the concessionaire. }\end{array}$ \\
\hline & $\begin{array}{l}\text { Reduction of the cost of the energy } \\
\text { bill (RCE) }\end{array}$ & $\begin{array}{l}\text { It evaluates how much the residence served by the DG } \\
\text { saves with the concessionaire's energy. }\end{array}$ \\
\hline \multirow{3}{*}{ Social } & Community acceptability (CA) & $\begin{array}{l}\text { Shows the acceptance of the community for the } \\
\text { installation of the DG. }\end{array}$ \\
\hline & $\begin{array}{l}\text { Expansion of the support network } \\
\text { (ESN) }\end{array}$ & $\begin{array}{l}\text { It considers the expansion of individuals and companies } \\
\text { that approached the community after the installation of the } \\
\text { DG. }\end{array}$ \\
\hline & Job creation $(\mathrm{JC})$ & $\begin{array}{l}\text { It assesses whether it generated any type of direct and } \\
\text { indirect employment during and after the installation of the } \\
\text { DG. }\end{array}$ \\
\hline
\end{tabular}

The elements of the Fuzzy set have a degree of pertinence that represents how much this element belongs to a given set. The relevance parameters were defined based on the Sustainness Performance Index (IDS) Table 7, as well as the intervals of the output function and are shown in Table 3 representing: the terms, parameters and display ranges for the variables of the membership function.

Table 3. Input and output membership function parameters

\begin{tabular}{ccccc}
\hline & \multicolumn{2}{c}{ Input } & \\
\hline Linguistic Terms & $\begin{array}{c}\text { Parameters of the triangular } \\
\text { membership function }\end{array}$ & $\begin{array}{c}\text { Display range } \\
\text { (Minimum-Maximum) }\end{array}$ \\
\hline Low & -36 & 0 & 36 & $0-100$ \\
\hline Medium & 19 & 50 & 80 & $0-100$ \\
\hline High & 64 & 100 & 136 & $0-100$ \\
\hline \multicolumn{6}{c}{ Output } \\
\hline Linguistic Terms & $\begin{array}{c}\text { Parameters of the triangular } \\
\text { membership function }\end{array}$ & $\begin{array}{c}\text { Display range } \\
\text { (Minimum-Maximum) }\end{array}$ \\
\hline Very Low & -19 & 0 & 22 & $0-100$ \\
\hline Low & 12 & 23 & 43 & $0-100$ \\
\hline Medium & 32 & 46 & 62 & $0-100$ \\
\hline High & 53 & 69 & 85 & $0-100$ \\
\hline Very High & 75 & 100 & 119 & $0-100$ \\
\hline
\end{tabular}




\section{Definition of Fuzzy rules}

The knowledgebase, also called the rules base, was built after defining the input and output variables and the membership functions. The models for obtaining the DG related sustainability impact index were built and 27 rules for the input variables, of the "If - then" type, were elaborated to express the relationship between the antecedents and the consequences (Table 4). The established rules activate the membership functions and define the degrees related to each Fuzzy set so that the values assigned to the input variables are observed and analyzed. For example, Rule 1 expresses the following condition: if EA, GW and LCH are low, then the environmental impact index will be very low. Degrees assigned to output; very low (VL), low (L), medium $(M)$, high $(H)$, very high $(V H)$.

Table 4. Basis of rules for the Fuzzy model for assessing the DG related sustainability in rural communities

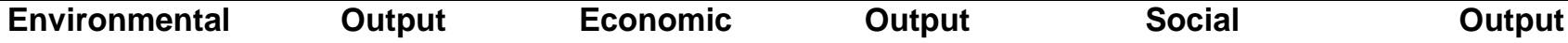

\begin{tabular}{|c|c|c|c|c|c|c|c|c|c|c|c|}
\hline EA & GW & $\mathrm{LCH}$ & & CS & IP & RCE & & $\mathrm{CA}$ & ESN & $\mathrm{JC}$ & \\
\hline Low & Low & Low & VL & Low & Low & Low & $\mathrm{M}$ & Low & Low & Low & $\mathrm{VL}$ \\
\hline Low & Low & Med & $\mathrm{L}$ & Low & Low & Med & $\mathrm{H}$ & Low & Low & Med & $\mathrm{VL}$ \\
\hline Low & Low & High & $M$ & Low & Low & High & $\mathrm{H}$ & Low & Low & High & $M$ \\
\hline Low & Med & Low & $M$ & Low & Med & Low & $\mathrm{H}$ & Low & Med & Low & $L$ \\
\hline Low & Med & Med & $\mathrm{M}$ & Low & Med & Med & $\mathrm{H}$ & Low & Med & Med & $\mathrm{L}$ \\
\hline Low & Med & High & $\mathrm{H}$ & Low & Med & High & $\mathrm{VH}$ & Low & Med & High & $\mathrm{M}$ \\
\hline Low & High & Low & VL & Low & High & Low & $\mathrm{H}$ & Low & High & Low & $M$ \\
\hline Low & High & Med & $\mathrm{H}$ & Low & High & Med & $\mathrm{VH}$ & Low & High & Med & $M$ \\
\hline Low & High & High & $\mathrm{H}$ & Low & High & High & $\mathrm{VH}$ & Low & High & High & $\mathrm{H}$ \\
\hline Med & Low & Low & $L$ & Med & Low & Low & $L$ & Med & Low & Low & $\mathrm{VL}$ \\
\hline Med & Low & Med & $\mathrm{M}$ & Med & Low & Med & $\mathrm{M}$ & Med & Low & Med & $\mathrm{M}$ \\
\hline Med & Low & High & $\mathrm{VH}$ & Med & Low & High & $\mathrm{H}$ & Med & Low & High & $\mathrm{M}$ \\
\hline Med & Med & Low & $M$ & Med & Med & Low & $\mathrm{M}$ & Med & Med & Low & $\mathrm{M}$ \\
\hline Med & Med & Med & $\mathrm{H}$ & Med & Med & Med & $\mathrm{H}$ & Med & Med & Med & $M$ \\
\hline Med & Med & High & $\mathrm{VH}$ & Med & Med & High & $\mathrm{H}$ & Med & Med & High & $\mathrm{H}$ \\
\hline Med & High & Low & $\mathrm{H}$ & Med & High & Low & $M$ & Med & High & Low & $M$ \\
\hline Med & High & Med & $\mathrm{H}$ & Med & High & Med & $\mathrm{H}$ & Med & High & Med & $\mathrm{H}$ \\
\hline Med & High & High & $\mathrm{VH}$ & Med & High & High & $\overline{\mathrm{VH}}$ & Med & High & High & $\mathrm{H}$ \\
\hline High & Low & Low & $\mathrm{H}$ & High & Low & Low & VL & High & Low & Low & $\mathrm{M}$ \\
\hline High & Low & Med & $\mathrm{VH}$ & High & Low & Med & $L$ & High & Low & Med & $\mathrm{M}$ \\
\hline High & Low & High & $\mathrm{H}$ & High & Low & High & $M$ & High & Low & High & $\mathrm{H}$ \\
\hline High & Med & Low & $\mathrm{H}$ & High & Med & Low & VL & High & Med & Low & $\mathrm{M}$ \\
\hline High & Med & Med & $\mathrm{H}$ & High & Med & Med & $M$ & High & Med & Med & $\mathrm{H}$ \\
\hline High & Med & High & $\mathrm{VH}$ & High & Med & High & $\mathrm{M}$ & High & Med & High & $\mathrm{H}$ \\
\hline High & High & Low & $\mathrm{H}$ & High & High & Low & $\mathrm{M}$ & High & High & Low & $\mathrm{H}$ \\
\hline High & High & Med & $\mathrm{VH}$ & High & High & Med & $\mathrm{H}$ & High & High & Med & $\mathrm{VH}$ \\
\hline High & High & High & $\mathrm{VH}$ & High & High & High & $\mathrm{H}$ & High & High & High & $\mathrm{VH}$ \\
\hline
\end{tabular}

The Fuzzy model generates an index for each dimension of sustainability; this index is compared with the indexes generated in the spreadsheet (Table 5). The Fuzzy inference assesses the DG related sustainability perception based on the weighted average of the indexes obtained for each of the (economic, social and environmental) models. Moreover, the Matlab software allows us to modify the input values to verify their influence on the output variable.

From the developed model it is possible to perform simulations to predict the impact that the increase or decrease in the value of each input variable would cause in the sustainability index with the DG. Table 5 presents some simulations. 
Table 5. Fuzzy model simulations of DG sustainability impact.

\begin{tabular}{|c|c|c|c|c|c|c|}
\hline \multirow[t]{2}{*}{ Dimension } & \multirow[t]{2}{*}{ Simulation } & \multirow{2}{*}{$\begin{array}{l}\text { Max. } \\
(\%)\end{array}$} & \multirow{2}{*}{$\begin{array}{l}\text { Min. } \\
(\%)\end{array}$} & \multicolumn{3}{|c|}{ Global Index (\%) } \\
\hline & & & & Max. & Med. & Min. \\
\hline \multirow{3}{*}{ Environmental } & Environmental awareness (EA) & 69,00 & 46,70 & \multirow{3}{*}{92,00} & \multirow{3}{*}{69,00} & \multirow{3}{*}{7,00} \\
\hline & Reduces global warming (GW) & 69,00 & 46,70 & & & \\
\hline & Landscape change (LCH) & 92,00 & 46,70 & & & \\
\hline \multirow{3}{*}{ Social } & Community acceptability (CA) & 69,00 & 26,00 & \multirow{3}{*}{92,00} & \multirow{3}{*}{46,70} & \multirow{3}{*}{7,00} \\
\hline & $\begin{array}{l}\text { Expansion of the support network } \\
\text { (ESN) }\end{array}$ & 69,00 & 26,00 & & & \\
\hline & Job creation (JC) & 46,70 & 46,70 & & & \\
\hline \multirow{3}{*}{ Economic } & Cost System (CS) & 46,70 & 69,00 & \multirow{3}{*}{92,00} & \multirow{3}{*}{46,70} & \multirow{3}{*}{7,00} \\
\hline & Incentive policies (IP) & 69,00 & 46,70 & & & \\
\hline & $\begin{array}{l}\text { Reduction of the cost of the energy bill } \\
\text { (RCE) }\end{array}$ & 69,00 & 46,70 & & & \\
\hline
\end{tabular}

Based on rule viewer results, percentage errors were calculated considering the actual values and simulated values. The percentage errors observed in the variables environmental awareness (EA), reduction of global warming (GW) and change in landscape (LCH) were $46.7 \%$. The environmental impact index (EII) using DG showed an overall accuracy of $69 \%$. From the results of the rule viewer, it is possible to perform simulations to predict the impact that an increase or decrease in the value of each input variable would cause in the environmental impact index with the use of GD.

The three input variables had a positive impact on the output index when their values were increased, up to their maximum values. Similarly, when considering the minimum values of the variables, there was a negative impact on the output value.

In the simulation, when considering the maximum value of the variable EA and GW, there was a positive impact of $22.3 \%$ on the Ell with the use of the GD defined in the partially unsustainable category (Table 7 ). When considering the maximum value of the $\mathrm{LCH}$ variable in the Ell using DG, the positive impact was $45.3 \%$ in the intermediate category of sustainability according to Table 7.

In the simulation, considering the minimum value of the variable $E A, G W$ and $L C H$, there was no positive or negative impact on the Ell using the GD, I devise the absence of the Ell variation.

In the most positive scenario, the 3 input variables $(E A, L C H, G W)$ when using the maximum value at the same time, the Ell using the GD reached an index of $92 \%$ sustainable category see (Table 7). Therefore, even in the best-case scenario, despite traditional communities over the centuries, they have a harmonious relationship of respect and protection of nature, ensuring its survival in their territories [43] .Still, the results indicate the need for training for the use of new techniques and tools to potentiate the use of natural resources.

Considering the most critical scenario, the Ell with the use of GD reduces to $39.7 \%$ in the intermediate category of sustainability see (table 7). This information is useful to understand the need to plan and execute actions that can expand the use of natural resources with the use of renewable sources.

Based on rule viewer results, percentage errors were calculated considering the actual values and simulated values. The percentage errors observed in the variables community acceptability (CA), expansion of the support network (ESN) and job creation (JC) were $32.9 \%$ defined in the partially unsustainable category see (Table 7). The social impact index (SII) using the DG presented a general accuracy of $46.7 \%$ category of sustainability would see (Table 7).

From the results of rule viewer, it is possible to perform simulations to predict the impact that an increase or decrease in the value of each input variable influence the social impact index with the use of DG. The community acceptability (AC) and support network expansion (ESN) input variables had a positive impact on the output index when their values were increased, up to their maximum values. However, the varied job creation (JC) did not generate a negative or positive impact. Similarly, when considering the minimum values of the variables, the negative impact on the output value of the variables CA and ESN was considered, except for the variable $\mathrm{JC}$ that did not determine a positive or negative impact.

In the simulation, when considering the maximum value of the variable $A C$ and $E S N$, there was a positive impact of $22.3 \%$ on the SII using the DG falling into the partially unsustainable category see (Table 7 ). However, the maximum value of the JC variable in the SII did not cause any change. 
In the simulation, when considering the minimum value of the variable $C A$, ESN, there was a positive impact of $20.7 \%$ on the SII using the GD falling into the partially unsustainable category see (Table 7 ). When the value is minimal of the variable $\mathrm{JC}$, there is no change in The SIl using the GD.

In the most positive scenario the 3 variables (CA, ESN and JC) input at their maximum value at the same time, the SII using the DG reached an index of $92 \%$ sustainable category see (Table 7). Therefore, even in the best-case scenario, the results indicated the need for effective training actions, training for installation and maintenance of the system, as well as dissemination and clarification of the various uses of renewable sources. In a critical scenario the SII with the use of DG reduces to $39.7 \%$ category intermediary sustainability, it is suggested the intensity for the realization of effective actions that can generate greater use of the direct and indirect resources of DG.

Given the surface viewer results, it was possible to confirm that the three input variables were relevant for determining the value in the model output. The percentage errors observed in the input variables Incentive Policies (IP), reduction of energy bill cost (RCE) and costs system (CS) were $54.13 \%$ partially sustainable category see (Table 7).

The economic impact index (ECII) using GD presented a general accuracy of $46.7 \%$ category intermediate sustainability see (Table 7).

From the results of rule viewer, it is possible to perform simulations to predict the impact that an increase or reduction in the value of each input variable influences the ECII using GD. The input variables incentive policies (IP) and reduction of the cost of the energy bill (RCE) had a positive impact on the output index when their values were increased, up to the maximum values, however, the variable costs system (CS) had no negative or positive impact. Similarly, when considering the minimum values of the variables, it generated a negative impact on the output value of the variables RCE and IP. However, the CS variation had a positive impact.

In the simulation, when considering the maximum value of the variable IP and $R C E$, there was a positive impact of 22.3\%) in the ECII with the use of GD falling into the partially unsustainable category see (Table 7), When applied the maximum value of the Variable CS there was no change in the ECII, and in the simulation when applied the minimum value of the variables IP, RCE, there was no negative or positive impact. Therefore, when the minimum value of the Variable CS is adopted, it generates a $22.3 \%$ index in the ECIl evaluated in the partially unsustainable category see (Table 7).

In the most positive scenario the 3 input variables at their maximum value at the same time, the economic impact index with the use of GD reached an index of $92 \%$ sustainable category see (Table 7). Therefore, even in the best-case scenario, the results indicate the need to carry out effective actions, regarding the cost of the system, with incentive policies to make the system accessible to traditional communities, because the average income of families is in the range of $1 / 3$ to 1.5 minimum wages. In the scenario considered critical, the economic impact index with the use of GD is reduced to $39.7 \%$ intermediate category of sustainability see (Table 7). The data presented in this study contribute to understand the need of the community and develop actions aimed at income management, with the use of GD in traditional rural communities.

The results of the impact of DG sustainability obtained in the spreadsheet and diffuse inference in Matlab generated equivalent indexes (Table 6), thus confirming the consistency of the method.

Table 6. DG related sustainability indexes of the electronic $p$ and the Fuzzy.

\begin{tabular}{lcc}
\hline Dimension & Spreadsheet (\%) & Fuzzy DG Logic (\%) \\
\hline Economic & 55,67 & 46,70 \\
Social & 46,32 & 46,70 \\
Environmental & 45.27 & 69,00 \\
General impact & 49,08 & 54,10 \\
\hline
\end{tabular}

From the calculation performed by the model, the level of perception of the social, environmental and economic variables generated an index that was classified by the performance scale of the Sustainable Development Indicators (IDS) [47]. The IDS classification considers a scale from 0 to 100 divided into five intervals that present conditions that vary from unsustainability to sustainability (Table 7). 
Table 7. Sustainability rating performance.

\begin{tabular}{ll}
\hline Category & Weighting \\
\hline Sustainable & $79<$ index $\leq 100$ \\
Parcially sustainable & $51<$ index $\leq 79$ \\
Intermediate & $36<$ index $\leq 51$ \\
Parcially unsustainable & $19<$ index $\leq 36$ \\
Unsustainable & Index $\leq 19$ \\
\hline
\end{tabular}

Source: Adapted from the 'Performance Scales' of the Sustainable Development Indicators [47].

The value of the index for each dimension and the impact on the DG related sustainability (Table 8) was obtained from the average of the respondents' values and the IDS classification (Table 7). Respondents' perception of DG related sustainability resulted in a global index of $54.1 \%$, which falls within the intermediate category of the IDS. The value of the sustainability index according to this study represents the socioeconomic reality of the community based on the average income and education of the residents, being considered a positive value.

Table 8. DG related Sustainability in the rural community by Fuzzy index, degree of relevance and IDS classification

\begin{tabular}{lccl}
\hline Dimension & System index Fuzzy (\%) & Degree of relevance & Category \\
\hline Economic & 46,70 & Medium & Intermediate \\
Social & 46,70 & Medium & Intermediate \\
Environmental & 69,00 & Medium & Parcially sustainable \\
Impact on DG & 54,10 & Medium & Parcially sustainable \\
\hline
\end{tabular}

The simulation meets the previously stipulated principle of the greater the respondents' satisfaction with the input variable indicators, the greater the social, environmental and economic impacts on DG since the increase of any variable implies in increase the sustainability index of the DG. However, decreasing any of the values of the input variables decreases the output value (index). The assessed DG index was classified in parcially sustainable category (Table 7 ).

The Fuzzy logic made it possible to transform linguistic variables (qualitative data) into numerical values (quantitative data) for the classification of the DG related sustainability index in rural communities. The Fuzzy model developed in this work comprised 3 dimensions and 9 indicators, aggregated to express the perception of sustainability of the rural community through the implementation of DG. The data used in the research were compiled from the responses to the questionnaire applied in person in the quilombola rural community Monjolo.

One of the challenges was to quantify the main perceptions of the target population of the research, as well as maintain the coherence of the specifications of the sustainability parameters, in relation to the rural environment due to its characteristics presents some challenges for research such as this, in the case study, for example, the application of the face-to-face questionnaire, because rural communities do not have access to the Internet, difficult to access a theme little known for respondents, in addition, there are a basic level training and even illiteracy.

However, the measuring DG related sustainability in rural communities can encourages strategic actions to implement this energy generation system through consortia, cooperatives, funding agencies and public policies to encourage, subsidize and implement DG connected to the power grid. DG can also contribute to keeping rural producers in the countryside, especially young people, who have migrated to the capitals since the United Nations (UN, 2018) estimates that by $205070 \%$ of the world population will live in areas where represent only $5 \%$ of the Earth's land area. The economic dimension of the electronic spreadsheet had the greatest impact on the study community (Table 3). The second major impact on the spreadsheet was the social dimension that is associated with the community organizational structure. However, the greatest impact obtained in the Fuzzy inference model was from the environmental dimension, with emphasis on the variable $\mathrm{LCH}$. 


\section{CONCLUSION}

This study aims to develop a DG related sustainability assessment model in rural communities, based on a fuzzy inference system, as support for providing information on scenarios with environmental, economic and social impacts. The result obtained with the Likert scale for the DG related sustainability index is $49.08 \%$, with the economic dimension having the greatest impact of $55.67 \%$. The impact assessment on DG based sustainability analysis, developed in the proposed Fuzzy system, results in $54,1 \%$ as a numerical output value. The sustainability index generated by the Fuzzy model proposed here is classified in parcially sustainable category. This result indicates the relevance of the impact of DG on the three levels of sustainability that were assessed.

The variable with greatest impact among the set of variables considered is the "change of landscape". This represents an environmental dimension. In the economic dimension, the variable cost of the system stands out because it has the greatest negative impact, the variable stems and PI have the same degree of impact. While in the social dimension, the variables CA and ESN have the same score.

It was observed that there is a correlation between the results obtained by the Fuzzy logic and the reality of the quilombo after the installation of the DG in 2014. The changes in habits adopted by the family that lives daily with the DG system are notorious. The researcher observed the following changes: more rational and efficient use of energy, such as bath time using an electric shower, installation of more economical lamps, willingness to install solar water heating systems and a water pump with energy photovoltaic solar. Given the above, the Fuzzy inference model allows a broader understanding of the sustainability variables of DG systems, including the identification of the most critical variables, to support more assertive decision making by managers, government organizations and private entities renewable energy business. In this way, it is possible to conduct more efficient actions in terms of maintenance, acquisition and implementation of DG systems in rural areas.

The Fuzzy inference model for assessing the sustainability of DG systems in rural communities proposed in this article contributes to the understanding of the indicators that make up the dimensions of the assessment system based on the concept of the triple bottom line (environmental, economic and social). These dimensions are influenced by categorical variables with a certain degree of subjectivity. The use of Fuzzy logic to evaluate the impacts on DG installations in the studied community generates results from diffuse modeling, obtaining a function for each variable, and an index for social, economic and environmental impacts. Furthermore, Fuzzy modeling makes it possible to transform linguistic variables into numerical values, which can lead to the generation of a global index representing the sustainability impact of DG in rural communities, according to the input values of the used variables.

The importance of the study lies in contributing to the implementation of public policies for quilombola peoples in the countryside in Brazil. Since quilombos in Brazil are among the most vulnerable communities in the country, is one of the historically excluded groups, victims of structural racism, on the margins of public policies, they face problems of regularization of their territory, suffer from the lack of citizenship and the abandonment and absence of affirmative public policies of the State. Reflecting on the reduction of these problems and possibilities of solutions, dg sustainability can be a tool to minimize the environmental impact of rural communities, help expand the social networks of these communities, generate income, expand knowledge of the use of renewable energy sources, and encourage more efficient use of electricity.

\section{REFERENCES}

1. Bauwens TB, Gotchev, Holstenkamp L. What drives the development of community energy in Europe? the case of wind power cooperatives. Energy Res. Soc. Sci., 2016.13:136-47.

2. ANEEL. Resolução Normativa № 482. [updated 2020 Jan 15; cited 2020 Jan 15]; Available from: http://www2.aneel.gov.br/cedoc/bren2012482.pdf.

3. Ackermann T, Goran A. Distributed Generation: A Definition Distributed generation: a definition. 2001. 7796(2016 August): p. 195-204.

4. Severino MM, Camargo IMdT, Oliveira MAGd. Geração distribuída: discussão conceitual e nova definição. 2008.

5. Guedes L, Santos E, Oliveira M. Alocação de geração distribuída em redes de distribuição radiais considerando análise de curva de carga. XIII Encontro Regional Ibero Americano do Comitê Nacional Brasileiro de, 2009.

6. Algarni AA, Bhattacharya K. Disco operation considering DG units and their goodness factors. IEEE Trans. Power Syst., 2009. 24(4): p. 1831-40.

7. Lora EES, Haddad J. Geração distribuída: aspectos tecnológicos, ambientais e institucionais. Rio de Janeiro: Interciência, 2006: p. 3-10. 
8. ANEEL. Geração Dsitribuida. [updated 2020 Jan 26; cited 2020 Jan 26]; Geração Distribuida]. Available from: https://app.powerbi.com/view?r=eyJrljoiZjM4NjM0OWYtN2IwZS00YjViLTIIMjItN2E5MzBkN2ZIMzVkliwidCI6ljQwZ DZmOWI4LWVjYTctNDZhMi05MmQ0LWVhNGU5YzAxNzBIMSIsImMiOjR9.

9. Lambert RJ, Silva PP. The challenges of determining the employment effects of renewable energy. Renew. Sust. Energ. Rev, 2012.16(7):4667-74.

10. Kumar A, et al. A Multi Criteria Decision based rural electrification system. IECON Proceedings (Industrial Electronics Conference), 2016: p. 4025-4030.

11. McKenna R, et al. Combining local preferences with multi-criteria decision analysis and linear optimization to develop feasible energy concepts in small communities. Eur J Oper Res, 2018.268(3):1092-110.

12. Kumar A, et al. Integrated assessment of a sustainable microgrid for a remote village in hilly region. Energy conversion and management, 2019.180:442-72.

13. Wu T, Xu DL, Yang JB. Multiple Criteria Performance Assessment for Decentralized Energy Systems: A Case Study. in 2019 5th International Conference on Information Management (ICIM). 2019. IEEE.

14. Trotter PA. Rural electrification, electrification inequality and democratic institutions in sub-Saharan Africa. Energy for Sustainable Development, 2016. 34: p. 111-129.

15. Büyüközkan G, Karabulut Y. Energy project performance evaluation with sustainability perspective. Energy, 2017. 119: p. 549-560.

16. Karakosta C, Askounis D. Developing countries' energy needs and priorities under a sustainable development perspective: A linguistic decision support approach. Energy Sustain Dev, 2010. 14(4): p. 330-338.

17. Kaya T, Kahraman C. Multicriteria renewable energy planning using an integrated fuzzy VIKOR \& AHP methodology: The case of Istanbul. Energy, 2010. 35(6): p. 2517-2527.

18. Amer M, Daim TU. Selection of renewable energy technologies for a developing county: a case of Pakistan. Energy Sustain Dev, 2011. 15(4): p. 420-435.

19. Sadeghi M, Ameli A. An AHP decision making model for optimal allocation of energy subsidy among socio-economic subsectors in Iran. Energy Policy, 2012. 45: p. 24-32.

20. Ren J, Sovacool BK. Prioritizing low-carbon energy sources to enhance China's energy security. Energy Conversion and Management, 2015. 92: p. 129-136.

21. Luthra S, Mangla SK, Kharb RK. Sustainable assessment in energy planning and management in Indian perspective. Renew. Sust. Energ. Rev. 2015. 47: p. 58-73.

22. Štreimikienè D, Šliogerienè J, Turskis Z. Multi-criteria analysis of electricity generation technologies in Lithuania. Renew. Energy, 2016. 85: p. 148-156.

23. Alfaro JF, et al. Improving rural electricity system planning: An agent-based model for stakeholder engagement and decision making. Energy Policy, 2017. 101: p. 317-331.

24. Zadeh LA. Fuzzy sets. Inf. Control., 1965. 8(3): p. 338-353.

25. Li Q. A novel Likert scale based on fuzzy sets theory. Expert Systems with Applications, 2013. 40(5): p. 1609-1618.

26. Zadeh LA, Fu KS, Tanaka K. Fuzzy sets and their applications to cognitive and decision processes: Proceedings of the us-japan seminar on fuzzy sets and their applications, held at the university of california, berkeley, california, july 1-4, 1974. 2014: Academic press.

27. Stefano NM, Laux RO, Gripa S. Avaliação da qualidade dos serviços por meio do fuzzy Multiple Criteria DecisionMaking (MCDM). Exacta, 2018. 16(1).

28. Rajak S, Vinodh S. Application of fuzzy logic for social sustainability performance evaluation: A case study of an Indian automotive component manufacturing organization. J. Clean Prod., 2015. 108: p. 1184-1192.

29. Arcos-Aviles D, et al. Fuzzy logic-based energy management system design for residential grid-connected microgrids. IEEE Trans Smart Grid, 2018. 9(2): p. 530-543.

30. Haider $\mathrm{H}$, et al. Sustainability assessment framework for small-sized urban neighbourhoods: An application of fuzzy synthetic evaluation. Sustain. Cities Soc., 2018. 36(May 2017): p. 21-32.

31. Yousefi H, Hafeznia H, Yousefi-Sahzabi A. Spatial site selection for solar power plants using a gis-based booleanfuzzy logic model: A case study of Markazi Province, Iran. Energies, 2018. 11(7).

32. Rosso-Cerón AM, et al. A novel hybrid approach based on fuzzy multi-criteria decision-making tools for assessing sustainable alternatives of power generation in San Andrés Island. Renew. Sust. Energ Rev, 2019. 110(2018 December): p. 159-173.

33. Hély V, Antoni JP. Combining indicators for decision making in planning issues: A theoretical approach to perform sustainability assessment. Sustainable Cities and Society, 2019. 44 (October 2018): p. 844-854.

34. Piacitelli LP. Avaliação da Sustentabilidade nas Universidades: uma proposta por meio da teoria dos conjuntos fuzzy. Brazil: repositorio unesp. 2019. 
35. Paiva DS, et al. Mercado voluntário de carbono: análises de cobenefícios de projetos brasileiros. Rev. Adm. Contemp., 2015. 19(1): p. 45-64.

36. UNFCCC. Benefits of the Clean Development Mechanism [updated 2012 Jan 01; cited 2018 Jan 01]; Available from: https://cdm.unfccc.int/about/dev_ben/ABC_2012.pdf.

37. Joshi A, et al. Likert scale: Explored and explained. Br. J. Appl. Sci. Technol., 2015. 7(4): p. 396.

38. Albaum G. The Likert scale revisited. J. Mark. Res. Soc., 1997. 39(2): p. 1-21.

39. Cronbach LJ. Coefficient alpha and the internal structure of tests. psychometrika, 1951. 16(3): p. 297-334.

40. Freitas ALP, Rodrigues SG. A avaliação da confiabilidade de questionários: uma análise utilizando o coeficiente alfa de Cronbach. in Simpósio de Engenharia de produção. 2005.

41. Almeida D, Santos MD, Costa AFB. Aplicação do coeficiente alfa de Cronbach nos resultados de um questionário para avaliação de desempenho da saúde pública. XXX Encontro Nacional de Engenharia de Produção, 2010. 15: p. 1-12.

42. Moura G. Comunidades quilombolas: conceito, autodefinição e direitos. [updated 2019 Nov 20; cited 2019 Nov 20]; Available from: http://www.palmares.gov.br/?p=19099.

43. Coelho-Junior MG, et al. Brazil's policies threaten Quilombola communities and their lands amid the COVID-19 pandemic. Ecosystems and People, 2020. 16(1): p. 384-386.

44. De Barros LC, Bassanezi RC. Tópicos de lógica fuzzy e biomatemática. Grupo de Biomatemática, Instituto de Matemática, Estatística e Computação Científica (IMECC), Universidade Estadual de Campinas (UNICAMP), 2010.

45. Costa Filho A. Traditional peoples and communities in Brazil: the work of the anthropologist, political regression and the threat to rights. Vibrant: Virtual Brazilian Anthropology, 2020. 17.

46. CONAQ. Coronavírus nos Quilombos. [updated 2020 Apr 26; cited 2020 Apr 26]; Available from: http://conaq.org.br/noticias/covid-19-chega-aos-quilombos/.

47. Kronemberger DMP, et al. Desenvolvimento sustentável no Brasil: uma análise a partir da aplicação do barômetro da sustentabilidade. Sociedade \& Natureza, 2008. 20(1): p. 25-50.

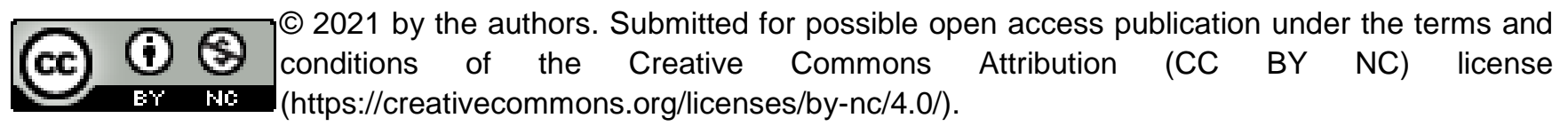

